\title{
Steering Wheel Tie Rod Fatigue Life Determination According to Turkish Mission Profiles
}

\author{
Arif Senol Sener \\ Department of Mechanical Engineering, Faculty of Architecture and Engineering, Istanbul Gelisim University, Avcilar, \\ Istanbul, Turkey. \\ (assener@gelisim.edu.tr)
}

\begin{abstract}
*Corresponding Author; Arif Senol Sener, Department of Mechanical Engineering, Faculty of Architecture and Engineering, Istanbul Gelisim University, Avc1lar, Istanbul, Turkey, Tel: +90 212422 7000, Fax: +90 212 422 7401, ssener@ gelisim.edu.tr
\end{abstract}

Received: 18.04.2016 Accepted: 01.06.2016

\begin{abstract}
In this study, Turkish customer automobile usage was determined by a questionnaire in order to form the Turkish Mission profile for a LCV (light commercial vehicle). A comparison between Turkish customer usage and a of the European County's mission profile was done. Referencing sale percentage of this vehicle and the region of the failures come out on other model vehicles were produced before and also Turkey's geographic and climate condition, a new test road was formed for this kind of vehicle. İn order to determine Turkey's rods fatigue characteristics a road test executed. About 50 road routes and some rough road's fatigue characteristics were acquitted with a LCV (Light Commercial vehicle) equipped with sensors. Collected data were elaborated with a software program such as; spike analysis, frequency analysis, artihmethic manipulation etc.. After that the general load spectrum of Turkey's roads belong to the steering wheel tie rod is formed. Rain-flow statistical counting method was applied steering wheel tie rod's signals in order to make fatigue comparisons meaningfully and other application. Then Fatigue analysis of the steering wheel tie rod according to MP (Turkish mission profiles) were calculated by using FEA (Finite Element Analysis) and verified by the Palsmgren-Miner rule.
\end{abstract}

Keywords: Customer usage, steering wheel tie rod, finite element analysis, fatigue analysis, Palmgren-Miner rule.

\section{Introduction}

Due to typical vehicle development time getting shorter, automobile firms look for advanced techniques to facilitate more rapid progress service load data acquisition and analysis method [1]. One of the most parameters of the vehicle performance is the fatigue life that is difficult verify in a normal process in a short time because fatigue problem arises in the long-mileage as well [2-3]. Hence, automobile companies uses new techniques in order to eliminate fatigue failures come out on prototype vehicles during is very important in terms of customer expectation and guarantee cost within the vehicle development time. The major parameters that effects the durability of a component are material, geometry and load spectrum $[2,4,5]$. The prediction of service life, reliability and safety are essential for the design process of road vehicle structures [6]. Fig. 1 shows the basic parameters necessary to complete the fatigue analysis based on finite element theory. These parameters are linear analysis results, dynamic load data, and the material specifications $[2,5]$.

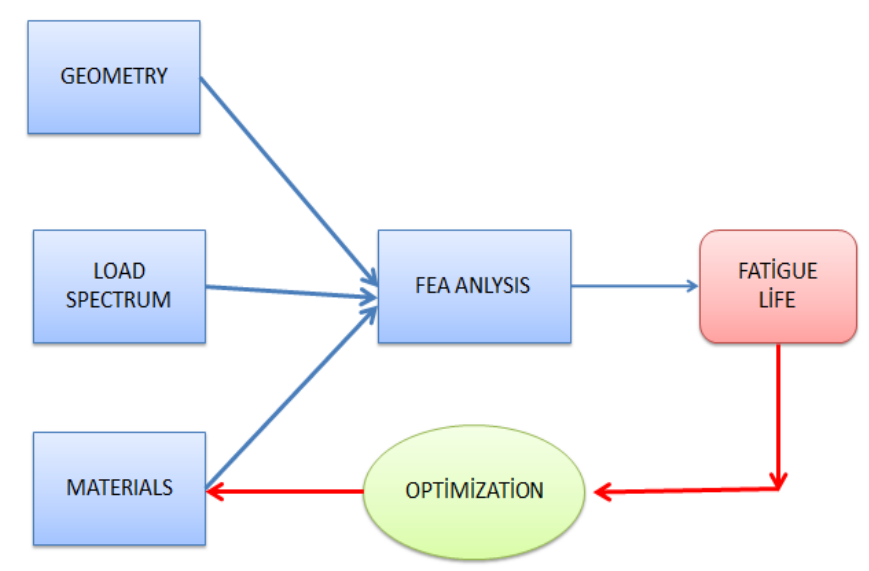

Fig. 1. Fatigue calculation based on the FEA [5]

For the service life of a product operational loading conditions are main importance [4]. The requirements on the strength, however, strongly depend on the loads in actual customer usage. Without appropriate knowledge of these loads one needs large safety factors, restrictive weight or cost 
reduction potentials [7]. By executing real test and computer analysis fatigue life prediction and the undamaged time of a vehicle component, which is affected by load spectrum, must determine referencing customer usage in which market component run [4]

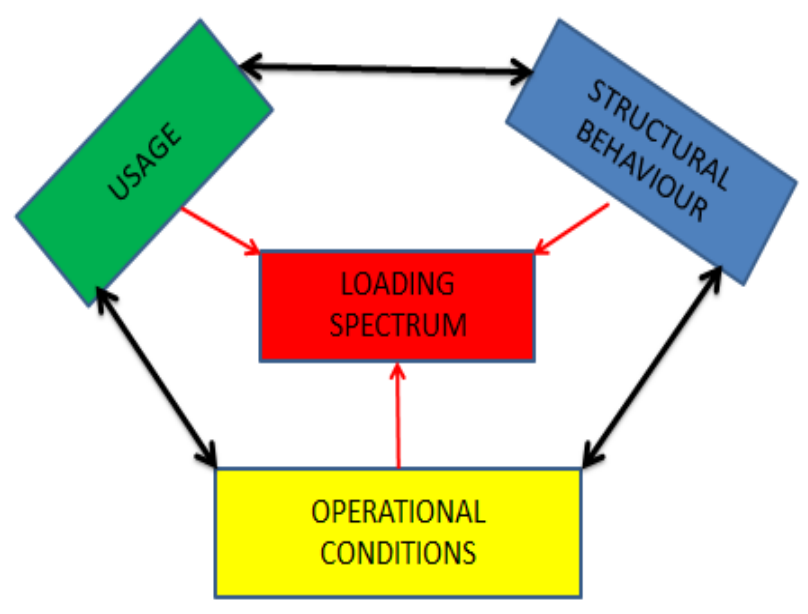

Fig. 2. Load spectrum parameters [2]

Essentially, automotive companies use four durability test methods: fatigue analysis based on Finite Element Analysis (FEA), test rigs, test benches (one particular actuator test), and accelerated test track. Rates of them in the four methods have advantages and disadvantage [6,7]. As a result, during design and verification process automobile companies use one or several methods together on automobile parts [3]. Durability test of a car, it encounter throughout their entire lifetime loads, type of usage, environmental and operational conditions will represent the entire load spectrum is provided by the determination $[3,4,6]$. Such a study on the most important and difficult is that how the representative load spectrum is determined. For the reason that all the methods used to date are either too weak or too extremely heavy [3].

The most popular method used for the determination of load spectrum for the whole life of vehicle is a customer usage based method [3-8].

One example of a customer usage study which includes dry and wet ground usage of tractor and agriculture as well as non-agriculture tractor usage and also regional tractor usage examination is a study on a tractor usage in India, which was performed by ETEC ( Eicher Tractors Engineering Centre) and ARIA ( Automotive Research Association of India [9]. Another example is a customer usage study performed by FIAT Co. for Brazilian and Italian markets. As we know that Brazil and Turkey have not special proving ground in order to make tests on standard fatigue road for development of new car models, FIAT Co. compared proving ground profile effects of public roads of Italy and Brazil in addition to customer usage effects on the vehicles by using frequency based fatigue life [10]. Another example is of a customer usage study was done by FIAT Co. AMOA (automobile mode of operation systems) on Ritmo 60 and Tipo1372 DGT [11]. And one of the other example is of customer usage study was performed by FIAT Co. for defining Turkish customer vehicle usage on a B segment vehicle Punto [12]. And one of the other example is of customer usage study was performed by TOFAS A.Ş. for defining Turkish customer vehicle usage profile and fatigue characteristic effect of Turkey's road profiles on a light commercial vehicles $[13,14,15]$.

The first important difference of the study compared to other studies is that the Turkish customer automotive usage profile was determined by a questionaries' method. Holiday time and the distance from the home which is one of the parameter of the questionnaire which has been monitored by FIAT Co. in 1993 [8]. FIAT had accepted the holiday concept as the interval of holiday more than three days and if the distance is far away more than $300 \mathrm{~km}$ from the residence area. In our study the holiday concept is restudied and holiday interval was decreased from one week to three days and the holiday distance was accepted as $300 \mathrm{~km}$ from the residence area. These parameters were applied on the Turkish customer in 2001 as a questionnaire [13]. The second important difference of the study compared to other studies is that those considered road roughness fatigue characteristic effects on the vehicle which were acquired from public roads (city roads, intercity, mountain and highway) were also mixed with some special proving ground data. Because Turkey no has not standard proving ground very heavy village roads including mostly potholes and sharp curves as well as bad rocked road profiles were defined quantity into the public roads $[2,13]$. The third important difference of this study compared to other studies is that road roughness fatigue data were mostly acquired from about 20 $\mathrm{km}$ of the sample roads, i.e., road fatigue characteristic data were not acquired from one city to another city totally. For example, Iveco and nCode Co. realized one study in 1999 in Australia [3, 13]. During this study they acquired 28 load measurements, 12 micro-strains, 2 weight conditions, 16 test track surfaces revealing 1280 signals with approx. 1.5 gigabytes and 26 road route surfaces revealing 280 signals with approx. 4 gigabytes. But in this study on 50 roads, approx. 45 gigabytes raw data were acquired and after processing the raw data, the total data file size was enlarged from 45 gigabytes to approx. 200 gigabytes [13].

In this study, the road fatigue characteristics were totally measured from one city to another city to find out the effect of different roads and to form new reliability roads that are necessary during the process and pre-series production around the interested factory. The design of test roads is extremely important for accurately simulating vehicle life. In the following sections, to determine a test track for a light commercial vehicle that benefited a lot from sensor data that one of driving shaft strain-gauge sensor, on test methodology is described

In the previous studies about the steering wheel tie rod, in 2006, a SUV's tie rod breaking problems were investigated [16]. In 2013 Static stress and natural frequency calculations of a steering wheel tie rod and steering wheel arm at an angle was done by Patil.M.A [17,18]. All equipment is made in the static structural analysis results for the model geometry as a single piece, it was determined that equipment is safe. A tool rod linkage parts of a minivan in 2014, was made separately by the modeling. The computer analysis performed and analytical improvements have been made according to 2000 Newton axial loads concerning in 
the specification of the FIR and the warranty is based on the application documents $[19,20]$.

In terms of time and cost, although all of them largely by the superior, as in the test rig, also the CEA in terms of weather and road conditions, process failures, driver errors, etc. are not expected to face assimilation a hundred percentages $[14,15]$.

In this article, the measured steering wheel tie rod raw data were collected, processed in order to find out MP (mission profile road characteristic) for a light commercial vehicle that benefited a lot from sensor data that one of steering wheel tie rod sensor, on test methodology is described.

\section{Methods and Analysis}

This method implements a large telephone survey designed to acquire information about the distribution of route types (city, extra urban, mountain, highway) the distribution of loads (driver without loads, driver and half load, driver and full load) customer education level, and the purpose of vehicle usage etc. [3, 13]. After acquiring the questionnaire results, a road test simulation is performed to collect data with an equipped vehicle or several equipped vehicles on public roads and special proving ground, during various maneuvers (braking, curving, accelerating), during power generation (engine and transmission components, in various location, on various type of roads (city, intercity, mountainous, rural), and by a test driver or multiple test drivers[6,13].Then the collected row data are elaborated like spike, filtering, manipulation etc. Then each road signal is subjected to statistically counting method 3D matrix or $2 \mathrm{D}$ range. So it is possible to make comparison of each road signal for each sensor. By multiplying the questionnaire with road type and target $\mathrm{km}$ to form the target mission profile which consists of road excitation signals taking into account $90^{\text {th }}$ percentile distribution of customer automotive usage, load, and the target MP is obtained for each sensor [3, 13].

The methodology is based on the following principle, if the same inputs are reproduced, then same damage will occur [3]. After forming MP, it is then possible to find mixes of tracks or rig drivers that match to the inputs for accelerated test including track or test rig that are corresponding to the same damage effect of MP. If the same inputs are maintained, matrix calculation of various forms will provide a scheme for assessing the mixture of road excitation signals, and for optimizing the test length or test time.

$\mathrm{A}[\mathrm{X} 1]+\mathrm{B}[\mathrm{X} 2]+\mathrm{C}[\mathrm{X} 3]+\ldots \ldots \ldots \ldots \ldots+\mathrm{Z}[\mathrm{Xn}]=[\mathrm{Y}]$

Where

A, B, C ....Z: Multipliers of test data,

$[\mathrm{X} 1],[\mathrm{X} 2] \ldots \ldots \ldots . . \mathrm{Xn}]$ : matrix of test measurements,

[Y]: matrix of customer target measurements.

This can be interpreted quite easily as: A times track X1, followed by times track X2, and so on, so that it gives the same effect as y of the target [3].

\section{Implementation}

In this study for road test acquisitions, FIAT Doblo Passenger car is selected as LCV. In Fig. 3 the algorithm of the study is presented.

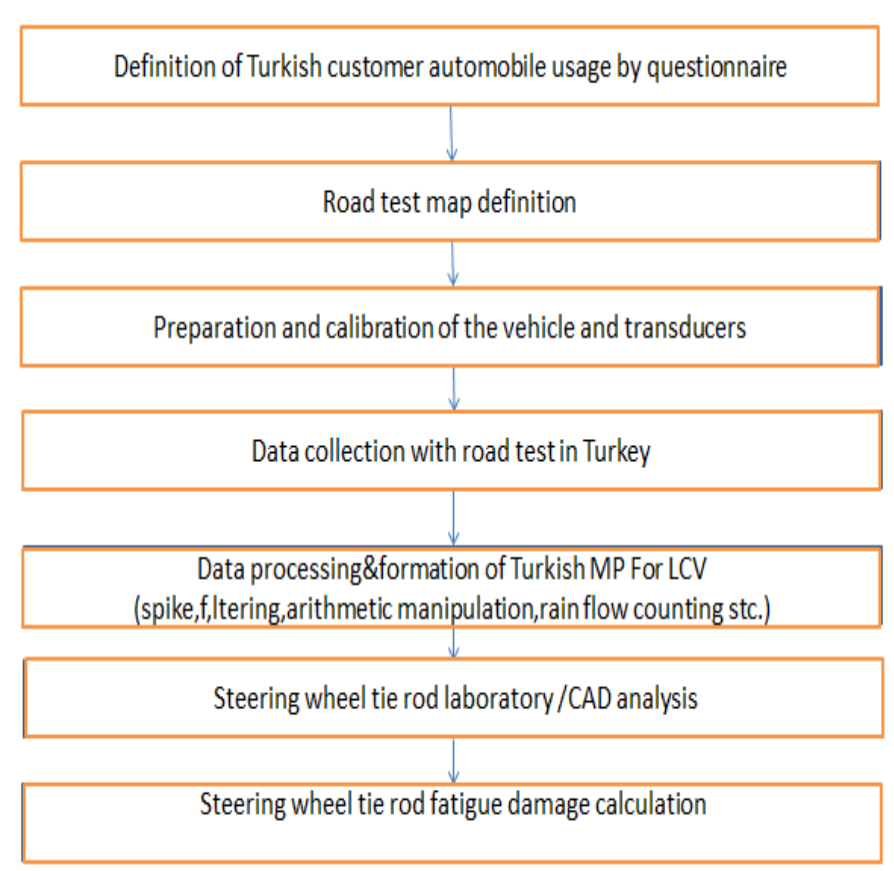

Fig. 3. Algorithm of the study

\subsection{Definition of the Turkish Profile -Questionnaire Application.}

As the questionnaire method allows a faster data collection, provides flexibility on data elaboration and reduces cost compared to the black box method as such, it was the method of choice in this study. The Turkish customer usage profile of a LCV that is used for transporting both goods and passengers was developed based on a questionnaire administered to Turkish customer with my support and also with the support of automotive dealers representing the LCV manufacturer[13].

\subsection{Definition of the Turkish Profile-Definition of Road Map.}

The defined test road map represents $90 \%$ of customer usage in Turkey. Those test roads in the road test map was designed taking reference of the sale percentages of LCVs according to region, customer complaints, previous model experiences, climatic conditions, and geography [3,12,13]. Roads were allocated in four groups: city road usage was found to be more common around the Istanbul district; Mountain roads were more common in the Black Sea region. Intercity roads, which include hot climatic and curved road condition, were found around the Mediterranean Sea. Roads in Central Anatolia were characterized by high altitudes, hot temperatures, and long distances between cities. For the highway road characteristics Istanbul-Ankara and Adana Gaziantep roads were subjected to data acquisitions. 


\subsection{Definition of the Turkish Profile-Data Acquisition to Define the Mission Profile Target.}

In this study, data acquisitions from the roads in Turkey were carried out with a vehicle equipped with sensors and driven over customers on chosen roads by an expert test driver and an engineer at full loads. Test vehicle was equipped with load transducers, two strain-gauges on the leaf spring, one strain-gauge on front left driving shaft, and one strain-gauge on the steering wheel tie rod. In Fig.4 and 5 subsequently demonstrate that the steering wheel tie rod with strain-gauge applied before and after fixing on the test vehicle. All sensor, transducers and strain gauges were calibrated and analyzed in the laboratory before being assembled on the test vehicle. Vertical acceleration caused by different maneuvers and road roughness were measured by accelerometers that were fixed at the bottom of shock absorber. Lateral and longitudinal body accelerations of the test vehicle were measured using two accelerometers positioned at the center of mass of the vehicle. Breaking maneuvers was measured by recording pressure in the hydraulic circuit. Two displacement sensors were used to define body movements. Ultimately the test vehicle speed, engine crank shaft rpm and temperatures (12 thermocouples) were digitally recorded [13]. The strain gauge application on the steering wheel tie rod and its assembly on the test vehicle are subsequently presented in Fig.4 and Fig.5.

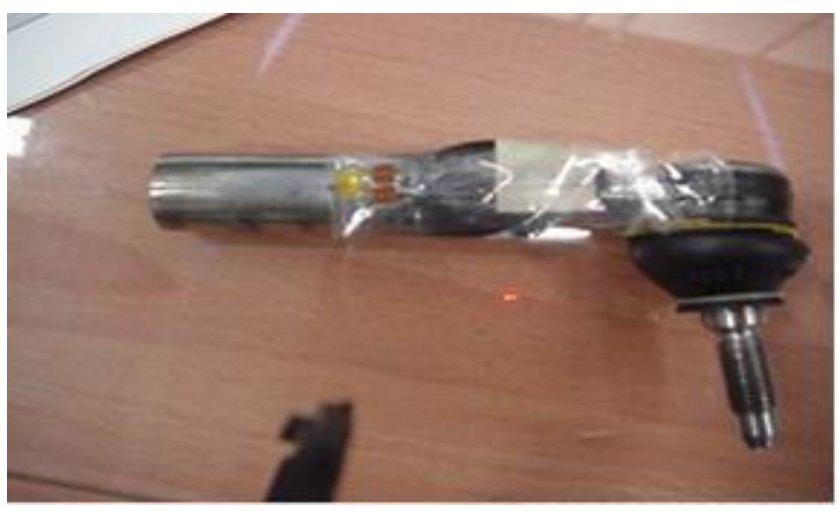

Fig. 4. Steering wheel tie rod with strain-gauge applied

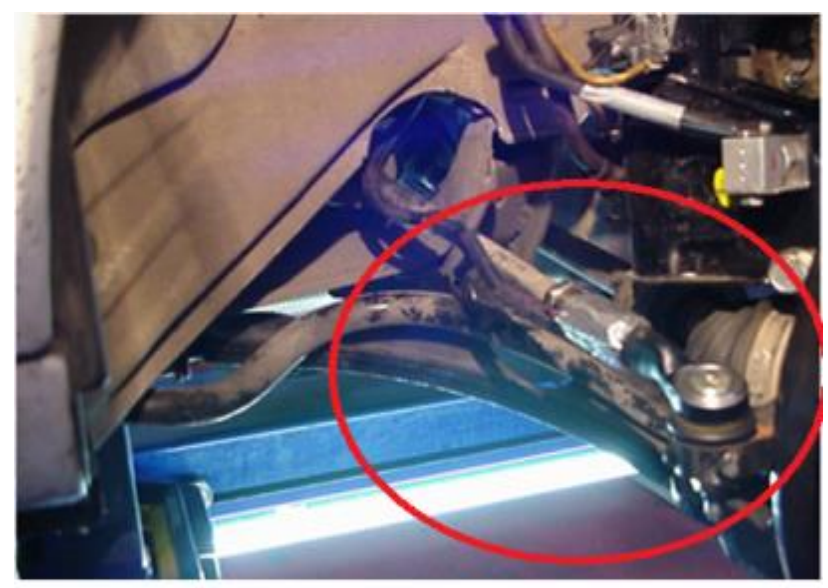

Fig. 5. Steering wheel tie rod with strain-gauge assembled on the vehicle

\subsection{Data Processing}

For fatigue data collection at time domain, we could not measure external loads directly. Instead of that we measured their reactions at certain points of vehicle part [21].The collected signals were processed by spike analysis, frequency analysis, filtering, arithmetic manipulation and statistical counting operation [8].

Spike Analysis: During data acquisition some "spikes" which were occurred due to environmental and physical factors, were eliminated by visual and statistical methods [22].

Filtering: As it is known that vehicle suspension parts frequency range of interest for fatigue analyses is between 40 $\mathrm{Hz}$ and $60 \mathrm{~Hz}$. For road simulation, it is generally accepted that excitation over $100 \mathrm{~Hz}$ can be neglected [13]. In Fig.6, low amplitude signals with frequencies above $100 \mathrm{~Hz}$ are not significant for fatigue analyses were removed from the original data by means of a low-pass filter $[12,13,14,15$, 22].

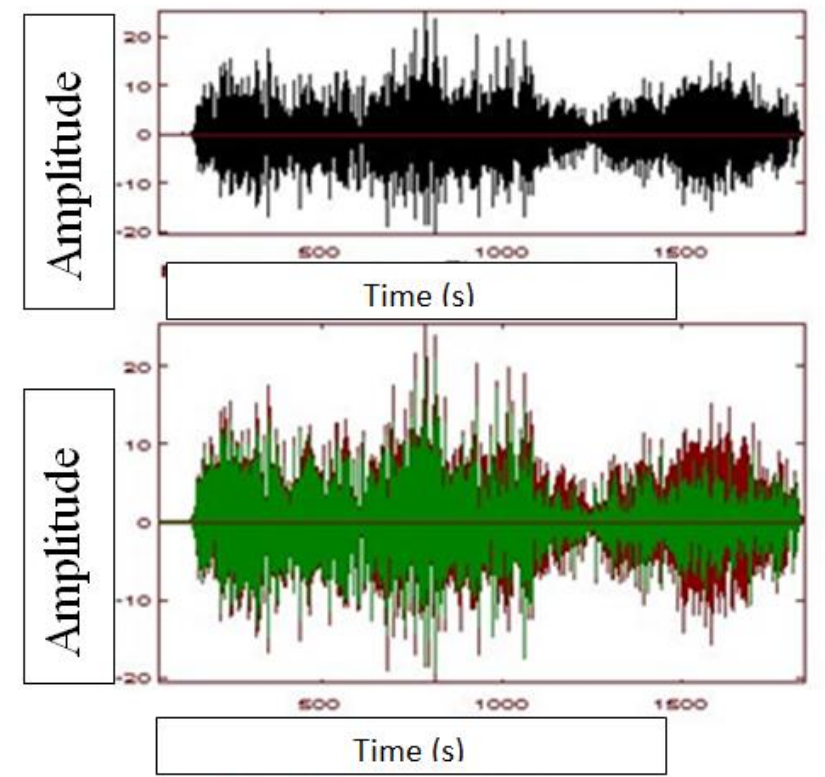

Fig. 6. Data filtering above $100 \mathrm{~Hz}$ [13]

Arithmetic Manipulations: In this study, acquired each test data which is not useful for fatigue life calculation is extracted before the vehicle movement is presented in Fig.7 $[13,22]$

Statistical Road Excitation Signal Counting: It is known that the road signal is formed by random and stationary signals that are time-varying. Time -varying signals should be converted to an equivalent value independent of time for comparison. The rain flow statistical counting method was applied to succeed in this conversion [23].The steering wheel tie rod strain-gauge axial data were reduced to foreseen $200000 \mathrm{~km}$ MP values taking into account mean amplitude $[12,13,14,15,24]$.

Forming Mission Profile Target: As the each acquired data had different lengths, the each measured data was normalized to convenient distance in kilometers (i.e., $1 \mathrm{~km}$ or $1000 \mathrm{~km}$ ) in order to compare and extrapolate for MP 
$[12,13,14,15]$. Each normalized measurement was classified according to road type (city, intercity, mountain, and highway); each road type was averaged within its class. Then each classified measurement was extrapolated to the estimated target $\mathrm{km}$ of MP and then multiplied by the percent Turkish customer usage distribution which the given road type based on the questionnaire. Fig. 7 illustrates that the histogram of steering wheel tie rod axial data MP (Turkish customer automobile usage fatigue characteristic of steering wheel tie rod for $200000 \mathrm{~km}$ ).
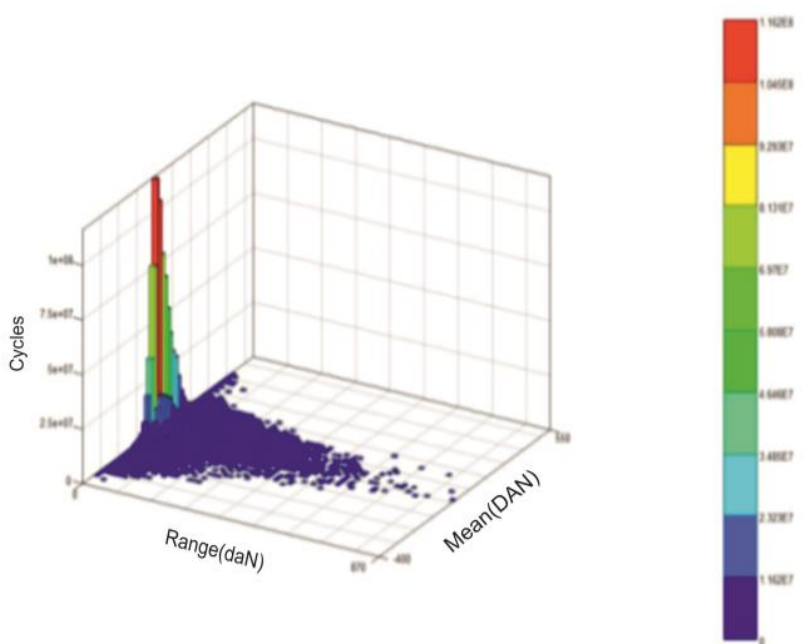

Fig. 7. Steering wheel tie rod Mission Profile rain-flow histogram $(200000 \mathrm{~km})$

\section{Simulation of Experimental Data by Finite Element Analysis}

\subsection{Steering wheel tie rod CAD model}

Fig. 8 shows the CAD model of the steering wheel ties rod was designed in Solidworks software program [25]. Tetra hydrogen solid elements were used for the steering wheel tie rod in order to precise modelling due to having a complex structure especially on the neck of the rod surface [26]. Then 3D CAD model of the steering wheel rod was exported to ANSYS program to perform FEA analysis. 3D CAD model of driving shaft was formed from 72233 tetra hexagon elements and 124827 nodes is presented in Fig.9 [26].

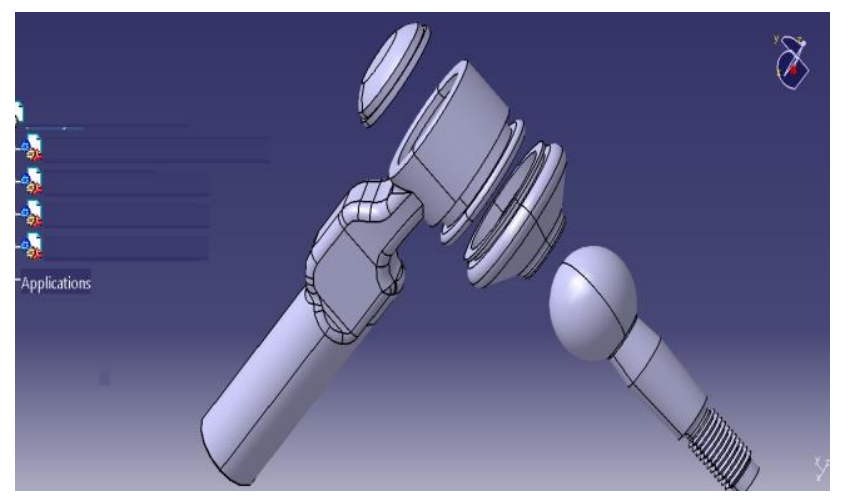

Fig. 8. CAD model of steering wheel tie rod

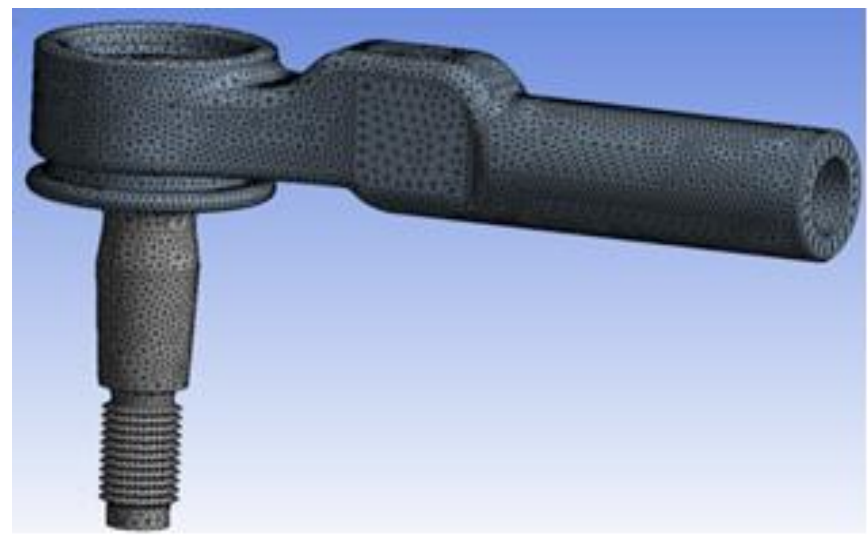

Fig. 9. FE Model of the steering wheel tie rod

\subsection{Boundary Condition}

The steering wheel tie rod's boundary condition of is illustrated in Fig.10. As it can be seen from illustration, the red arrow at the right surface of tie rod demonstrates the applied axial pulling load direction, which is allowed free only extension axis while the other balling rod side that is demonstrated with blue arrow that is connected to knuckle with a bold, is demonstrated and the fixed point is not allowed freely both rotation and shift every three axis [26, 27].

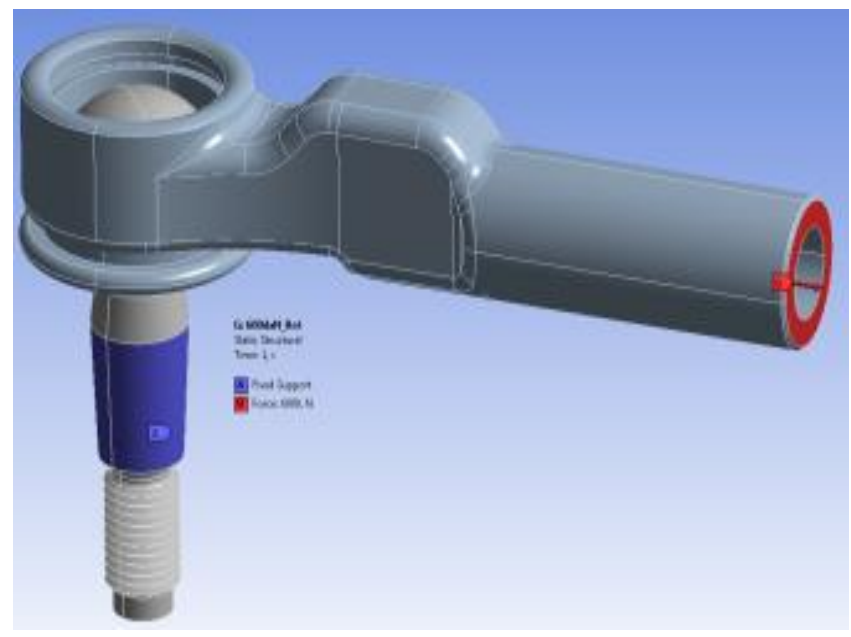

Fig. 10. Boundary conditions

The ball joint connection between the surface and the spherical guide surface around 3 degrees of freedom (DOF) has been defined links. Because the steering wheel tie rod is fixed from the each side both steering wheel cramayer shaft and the rack at the knuckle freedom is allowed to return are depicted. Here, in three axes of translational freedom $(x, y, z)$ of linear movement, the freedom of rotation in three axes $(\mathrm{Rx}, \mathrm{Rz}, \mathrm{Rz})$ represents rotation.

\subsection{Static and Fatigue Analysis}

Fig.11. shows the most critical load signal, which was acquired during road test in Turkey, of the steering wheel tie rod used for the linear static analysis of part. 


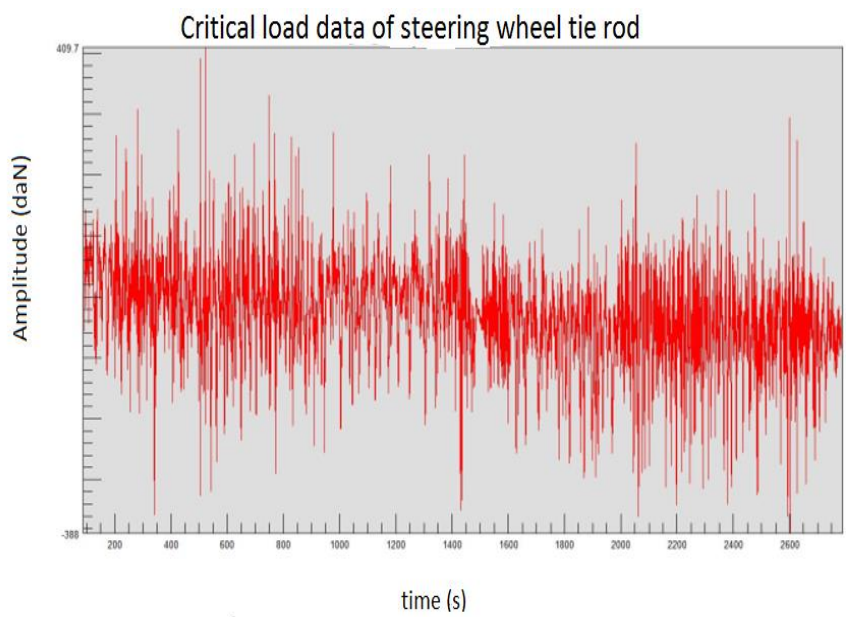

Fig. 11. Critical road data axial force -time signal of steering wheel tie rod

The linear static analysis of the steering wheel tie rod was performed using the most critical load that was picked up during road tests in Turkey is displayed in Fig.12. For the statistical analysis of steering wheel tie rod, the maximum load data, measured during the road test, horizontally 900 daN axial pulling forces was applied from the side of steering wheel tie rod connection by using the FE model. In Fig.12, it can be seen that after applying 900 daN axial pulling force on the spherical joint branches $0.0061938 \mu \varepsilon$ strain was derived. Simultaneously, the maximum nominal stress was found $1397 \mathrm{Mpa}$ at node 5796 according to the von-Misses method by means of the most critical load condition in the linear static analysis $[13,27]$.

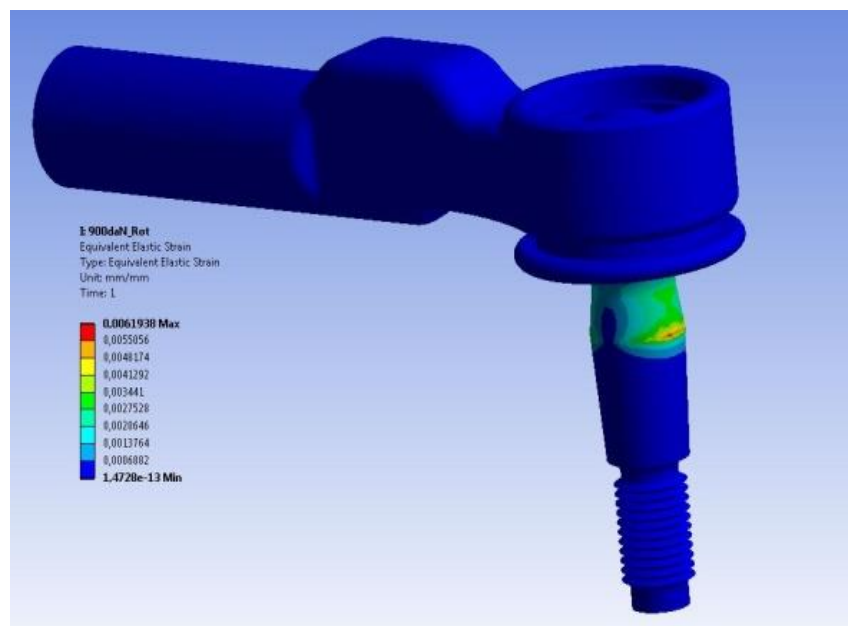

Fig. 12. Static strain analysis of steering wheel tie rod according to 900 daN axial force

Fig.13 shows the comparison of the steering wheel tie rod real bench test and CAD static analysis strain values. As it can be seen from the graphics, the vertical axis demonstrates physically applied axial force loads whereas the axial axis demonstrates derived unit normal strain on the driving shaft in laboratory and CAD during calibration test. Blue square symbol demonstrate us physically applied axial real force load on the steering wheel tie rod in lab while red triangle symbol shows us the CAD static analysis result after applying same loads on the FE model of steering wheel tie rod. When $100 \mathrm{daN}$ is applied $0.0009427 \mu \varepsilon$ by the physical test, $0.0006882 \mu \varepsilon$ by the computer analysis test were measured.

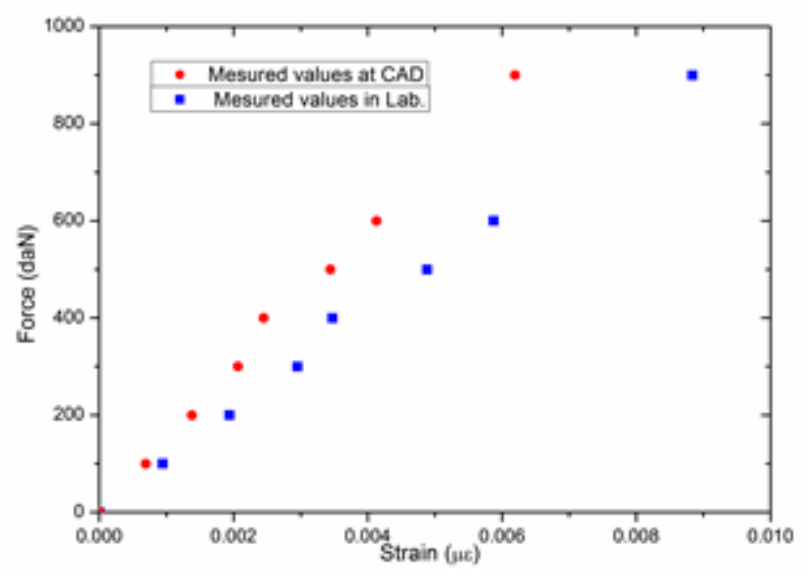

Fig. 13. Steering wheel tie rod real bench test and CAD static analysis strain values comparison

It is determined that the maximum stress is much lower than the actual yield stress of the steering wheel tie rod material yield stress. For these reason the S-N method was chosen [13, 27]. Fig.14 illustrates the Wohler line S (stress) $\mathrm{N}$ (number of cycles) of the material characteristics of the steering wheel tie rod [27].

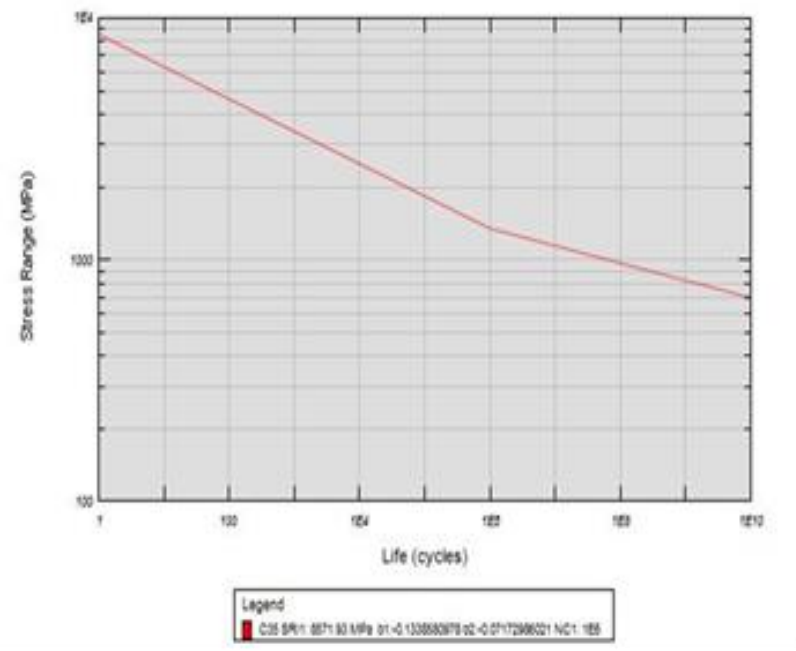

Fig. 14. S-N curve of the steering wheel tie rod

\subsection{Plamgren-Miner Analysis}

If a specimen is stressed at $\mathrm{n}_{1}$ of $\mathrm{N}_{1}$ cycles, the damage after $n_{1}$ cycles at $\sigma_{1}$ will be $n_{1} / N_{1}$ of the total damage, $D$, at failure. Similarly, for a second stress level test with lifetime $\mathrm{N}_{2}$ the corresponding damage per cycle is $\mathrm{D} / \mathrm{N}_{2}$. Thus the total damage at failure is $\mathrm{D}=\mathrm{Dn}_{1} / \mathrm{N}_{1}+\mathrm{Dn}_{2} / \mathrm{N}_{2}$ where $\mathrm{n}_{1}$ and $\mathrm{n}_{2}$ are total number of cycles at $\sigma_{1}$ and $\sigma_{2}$ respectively. The Plamgren- Miner rule states that failures will occur if, $\mathrm{n}_{1} / \mathrm{N}_{1}$ ${ }_{+} \mathrm{n}_{2} / \mathrm{N}_{2}+\mathrm{n}_{3} / \mathrm{N}_{3}+\ldots \ldots . .1$ [28]. In this study the PlamgrenMiner rule is applied. Fatigue CAD analysis of steering wheel tie rod in terms of fatigue damage is given in Fig. 15. Fatigue damage is not occurred. 


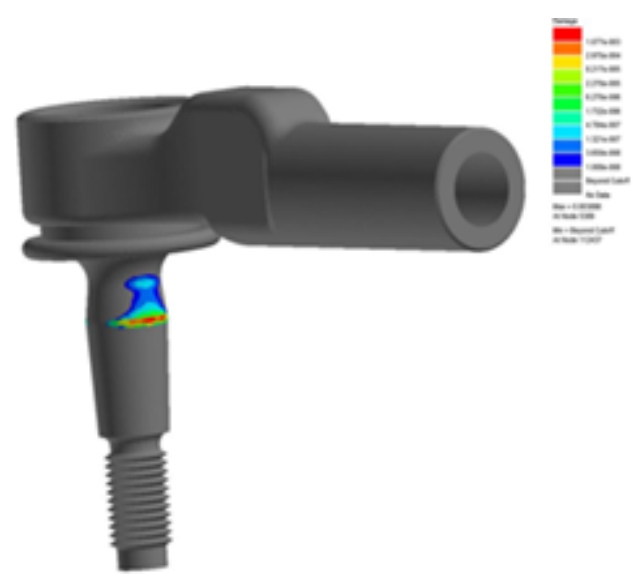

Fig. 15. Fatigue damage of steering wheel tie rod applying $200000 \mathrm{~km}$ MP data

\section{Result}

Resulting from the questionnaire, the automotive usage of Turkish customer for a LCV is defined in Table 1.

Table 1. Turkish customer usage of LCV-Passenger [13]

\begin{tabular}{|l|r|}
\hline City Usage & $50 \%$ \\
\hline Intercity & $24 \%$ \\
\hline Highway & $20 \%$ \\
\hline Mountain/Hill & $6 \%$ \\
\hline
\end{tabular}

When the derived data are analogue to one of the European countries, the most important difference is found in the amount of city usage, which is $50 \%$ in Turkey.[12,13]. These load spectra have been verified in terms of a fatigue damage analysis according to the Palmgren-Miner damage rule. From the MP test in Turkey 900 daN like the maximum axial force load is reached. Fig.16 shows 2D graphics of steering wheel tie rod data of mission profile $200.000 \mathrm{~km}$.

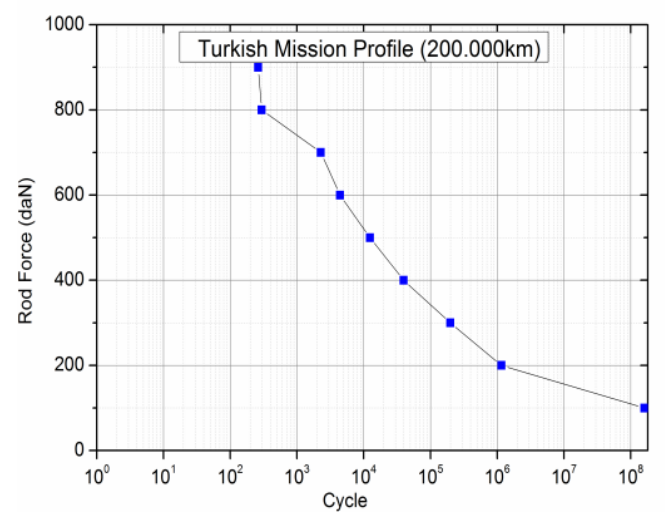

Fig.16. Steering wheel tie rod data of mission profile $200.000 \mathrm{~km}$

\section{Conclusion}

In this study, Turkish customer usage profile was developed based on a questionnaire handed out to Turkish light commercial vehicle users [13]. A comparison of LCV usage between a European country and Turkey was presented. It discovered that the Turkish customers use this type of vehicle for city driving twice as much as typical users in a European country $[12,13]$.

After processing, classifying and normalizing different signals fatigue chcarcteristics of Turkey's roads ( mission Profile ) for $200.000 \mathrm{~km}$ in normal dirving condision were determined mathematicallyfor this kind of vehicle $[14,15]$.

It is determined that the lineer analysis method that is used in virtuel analysis of the structure gave more precise result.

Based on this analysis, critical force and stress ranges have been defined and recorded in a database for future reference during development projects.

Tetra and hexagon type 3D elements have been used in FEA models of steering wheel tie rod. Tetra type elements were found to give more precise results in terms of frequent and geometrical aspect for this kind of component.

It has been observed that $\mathrm{S} / \mathrm{N}$ fatigue method was more appropriate according to steering wheel tie rod's critical data amplitude which is lower than Wöhler line.

It has been verified that there was no fatigue damage occurred on the steering wheel tie rod after applying the Turkish customer profile (MP_200000 km).

It has been observed that computer aided analysis can be used as an alternative for laboratory tests because the results that were obtained from both methods were quite similar

\section{Acknowledgements}

TOFAS A.Ş. is acknowledged for supporting this research.

\section{References}

[1] J. P. Heyes, X. Lin, A. Buczynski, and M. Brown: Application of biaxial plasticity and damage modeling for the life prediction and testing of automotive components, Proc. of the 5th International Conference on Biaxial/Multiracial Fatigue and Fracture, Cracow, Poland 1997

[2] V. Grubisic, Determination of load spectra for design and testing. International Journal of Vehicle Design, 1994. 15(1-2): pp. 8-26.

[3] Case Study - Complete Customer Usage Profiling Example

[4] N.W. Bishop and F. Sherratt, Finite element based fatigue calculations. USA (2000): NAFEMS. DOI:10.1111/j.1460-2695.1990.tb00604.x

[5] NCode International Inc.\&MSC Software Corporation : User manuel MSC Corporation ,Los Angles, USA(1998)

[6] V.Grubisic, Criteria and methodology for lightweight design of vehicle components. 1986: Fraunhofer-Inst. für Betriebsfestigkeit. 
[7] K.Ahlin, J. Granlund, and F. Lindstrom, Comparing road profiles with vehicle perceived roughness. International Journal of Vehicle Design, 2004. 36(2-3): p. 270-286.

[8] M.Fantacchiotti. and M. Vianello. Gradual improvement to the vehicle reliability up to the target value. in 4th International Conference ATA, Firenze. 1994.

[9] P.Paul, et al., Techniques for Accelerated Design Validation of Tractor Chassis. 2001, SAE Technical Paper, 01 pp.1-50

[10] F. D’Aprile, et al., Structural characterization of a vehicle on a rig test versus different road profiles: analysis of experimental results. ATA-TORINO-, 2001. 54(7/8): p. 251-261

[11] C.Marchesani. F. Parmigiani, and M. Vianello (1979) Integrated method to define the mission profile of a passenger car 'FIAT Auto S.p.A., Study Report (in Italian)

[12] V. Pizzari, Ricerca del profilo di Missione vetture segment B Turchia,. 1998: Turkish Ciklo Relazione Prot. No. 1 -1998, D.T.S.V. Affidabilita' e Terreni Prova Laboratorio Misure (in Italian), Arese.

[13] A.S.Sener, Fatigue life determination of the leaf spring on the light commercial vehicle according to Turkish Mission Profile (in Turkish). 2003, Yildiz Technical University.

[14] A.S.Sener, Finite Element Based Vehicle Component Fatigue Life Assessment According to a Customer Usage Profile. Materials Testing, 2014. 56(3): p. 198207.Magnetism, 3rd ed., vol. 2. Oxford: Clarendon Press, 1892, pp.68-73. (Book)

[15] A.S.Sener, Fatigue life assessment of the driving shaft of a LCV by FEA using customer correlation data Materials Testing, 2016. 58(4): p. 325-332, DOI.10.3139/120.110861H.

[16] A.Falah, M. Alfares, and A. Elkholy, Failure investigation of a tie rod end of an automobile steering system. Engineering Failure Analysis, 2007. 14 (5): p. 895-902.
[17] M.A.Patil, D. Chavan, and M.K.U.S. Ghorpade, FEA of Tie Rod of Steering System of Car. International Journal of Application or Innovation Engineering and Management, 2013. 2(5): p. 222-227.

[18] J.Kim, J. et al., Structural design of an outer tie rod for a passenger car. International Journal of Automotive Technology, 2011. 12(3): p. 375-381.

[19] M.K.Pehlivan and M.Ozsoy, Computer aided structural analysis of rot head. Bilecik Şeyh Edebali Universitesi Fen Bilimleri Dergisi, 2014. 1(1): p. 45-51

[20] Regulation on Warranty application basis ( in Turkish ) 2003.

[21] M.Gobbi and G. Mastinu, Expected fatigue damage of road vehicles due to road excitation. Vehicle System Dynamics, 1998. 29(S1): p. 778-788.

[22] MSC. Software GmbH nSoft volumes 5.2 User Manuel. 1999.

[23] ASTM Standard E 1049-85, Philadelphia, USA. 1997.

[24] N.Bishop et al., 'Analytical Fatigue Life Assessment of Vibration Induced Fatigue Damage '. MSC World Users Conference, Universal City, CA, 1995.

[25] SolidWorks. 2011.

[26] ANSYS. 2012.

[27] The Ncode Book of Fatigue Theory, Ncode Technical Reference Book V4.3. Document rel 1.0, MSC Corporation. 2000.

[28] M.A.Miner, Cumulative damage in fatigue. Journal of applied mechanics, 1945. 12(3): p. 159-164. 